\title{
How does reduction in pain lead to reduction in disability in patients with musculoskeletal pain?
}

This article was published in the following Dove Press journal:

Journal of Pain Research

\author{
Maryam Shaygan' \\ Andreas Böger ${ }^{2}$ \\ Birgit Kröner-Herwig ${ }^{3}$ \\ 'Community Based Psychiatric Care \\ Research Centre, Faculty of Nursing and \\ Midwifery, Shiraz University of Medical \\ Sciences, Shiraz, Iran; ${ }^{2}$ Pain Management \\ Clinic at the Red Cross Hospital, Kassel, \\ Germany; ${ }^{3}$ Department of Clinical \\ Psychology and Psychotherapy, Georg- \\ Elias-Müller-Institute of Psychology, \\ Georg-August-University, Göttingen, \\ Germany
}

\begin{abstract}
Purpose: Reduction in pain following multidisciplinary treatment is most often associated with a reduction in disability. To further elaborate the relationship between pain intensity and disability, the present study investigated three main questions: first, whether multidisciplinary treatment leads to a significant improvement in pain, disability and psychological variables (depression, pain acceptance and catastrophizing). Second, it was examined whether pain reduction may account for significant changes in the psychological variables (pre- to followup change scores). Finally, it was analyzed whether the psychological changes mediate the association between reduction in pain and in disability after controlling for age, sex and pain history.
\end{abstract}

Patients and methods: Patients suffering from chronic musculoskeletal pain $(n=279)$ attended a German inpatient multidisciplinary program lasting 15 consecutive days on average, with self-report data collected at pretreatment, posttreatment and three-month follow-up.

Results: Repeated measures ANOVAs showed a significant improvement in pain intensity, disability, pain acceptance, catastrophizing and depression at posttreatment and follow-up. Univariate regression analyses revealed that changes in pain intensity accounted for significant changes in depression, pain catastrophizing and pain acceptance (pre- to follow-up change scores). The results of Multiple Mediation Procedure showed that pain reduction did affect reduction in disability through improvement of depression, catastrophizing and acceptance.

Conclusion: Our findings support a cognitive-behavioral model of pain that posits an important role for pain-related cognitive and emotional processes in long-term outcomes following multidisciplinary pain treatment, in particular for the modulation of disability due to pain. The results add evidence to the notion that pain-related cognitions are dynamic features varying over time dependent on the internal situation.

Perspective: The current findings are relevant to the management of patients with musculoskeletal pain. The results support the notion that, in contrast with the view of enduring personality traits, pain-related cognitions and emotions reflect a situational response that varies over time.

Keywords: musculoskeletal pain, disability, psychological variables

\section{Introduction}

Musculoskeletal pain is common among the general population ${ }^{1,2}$ and often presents in several anatomical sites concomitantly. ${ }^{3,4}$ Low back pain, fibromyalgia and osteoarthritis are major musculoskeletal conditions. ${ }^{1,2}$ Musculoskeletal conditions are the common cause of severe pain and disability. ${ }^{5-7}$ They account for $30.5 \%$ of all years lived with disability ${ }^{6}$ and are the second most common cause of loss of
Correspondence: Maryam Shaygan Faculty of Nursing and Midwifery, Shiraz University of Medical Sciences, P.O. Box 713451359, Shiraz, Iran

Email m2620.shaygan@gmail.com 
time from work. ${ }^{7}$ Thus, musculoskeletal pain has a dramatic impact on the lives of affected individuals and a substantial economic impact on society.

According to cognitive-behavioral models of pain, the presence of pain is not sufficient condition for the development of disability. ${ }^{89}$ These models typically posit that affective and cognitive factors such as depression and catastrophizing, a cognitive style characterized by magnification, rumination and helplessness, ${ }^{10}$ can modulate perceived pain and disability in patients. Also, based on acceptanceoriented forms of cognitive-behavioral perspective, ${ }^{11}$ pain acceptance plays an important role in coping with pain and its associated problems. ${ }^{12,13}$ Acceptance of pain is defined by the acknowledgment that one can be in pain and at the same is capable of making efforts to live a satisfying life. ${ }^{12}$ Depression, ${ }^{14,15}$ catastrophizing ${ }^{14,16,17}$ and acceptance ${ }^{12-15}$ are among the most widely studied factors modulating pain and disability.

Based on cognitive-behavioral perspective, pain treatment programs are effective if they alter patient cognitive and behavioral responses to pain. ${ }^{8,9}$ Since a lack of attention to the psychological factors can lead to failures in the treatment of disabled pain patients, ${ }^{8}$ multidisciplinary interventions have gained more and more acceptance regarding the treatment of patients.

Reduction in pain following multidisciplinary treatment is most often associated with a reduction in disability. ${ }^{15,18,19}$ A growing body of evidence assesses mediating factors of the relationship between pain intensity and disability. However, most of this evidence is limited by cross-sectional designs. ${ }^{20-24}$ To date, very few longitudinal studies have identified mediators of the outcome of disability following treatment. ${ }^{22,24}$ Reduced catastrophizing, ${ }^{25-27}$ increased self-efficacy ${ }^{25,28,29}$ and an increase in psychological flexibility ${ }^{30,31}$ were the factors most often tested as mediators in the longitudinal studies. However, the longitudinal findings are inconsistent. ${ }^{24}$ Moreover, the most existing longitudinal studies are based on patients with back pain, ${ }^{24,32,33}$ included a small sample size ${ }^{30}$ and focused on either psychological ${ }^{30}$ (eg, cognitive-behavioral therapy) or physical ${ }^{34}$ treatments as predictor variables. In fact, most longitudinal studies provided insight into how the effectiveness or ineffectiveness of a specific treatment influences pain disability. Available data do not give us information about the mechanisms of action that lead to a reduction of disability following pain reduction (as a clinical feature) after multidisciplinary programs. The present study aimed to evaluate how pain reduction influences reduction in disability and the role of theoretically relevant psychological factors as potential mediators.

Before attempting to explain psychological factors as mediators of the relationship between reduction in pain and disability, it is critical to clarify whether changes in pain intensity may account for significant changes in psychological factors. Previous research mostly examined whether psychological (eg, cognitive) variables influence pain, but not whether the severity of pain has an effect on cognition. Many prior studies have proposed that painrelated cognitions such as catastrophizing are an enduring trait rather than a dynamic state. ${ }^{35-38}$ However, a dynamic view of pain-related cognitions has also been proposed by some other research. ${ }^{39,40}$ If pain-related cognitions (eg, catastrophizing and acceptance) are dynamic states mediating the association between reduction in pain and disability, improvement in pain should account for substantial changes in these factors. However, as suggested by Mansell et al, where evidence is lacking or controversial, it is important to test the associations which are pre-requisites for mediation, through preliminary analysis before conducting mediation analysis. ${ }^{24}$

To further elaborate the relationship between pain intensity, disability and psychological factors, the present study investigated three main questions:

First, it tries to validate results of earlier studies ${ }^{15,18,19}$ by showing that multidisciplinary treatment leads to significant improvements in pain intensity, disability and psychological variables (depression, pain catastrophizing and acceptance) at the time of discharge and 3-month follow-up. The authors expect significant positive changes in these variables at the two assessment periods.

Second, as a preliminary analysis, it was determined whether pain reduction may account for significant changes in psychological factors (pre- to follow-up change scores).

Finally, it was analyzed whether the expected psychological changes mediate the association between reduction in pain and in disability. Looking at the cognitive-behavioral models that hypothesize a central role for cognitiveemotional responses in coping with chronic pain and its associated problems, ${ }^{8,9}$ it was assumed that pain reduction would influence reduction in disability through improvement of depression, pain catastrophizing and acceptance. As the disability is known to associate with sex, age and pain history, ${ }^{41,42}$ these variables were controlled for in the mediation analysis. 


\section{Methods}

\section{Participants}

Participants were 300 consecutive patients suffering from a chronic musculoskeletal pain condition. All of these patients failed previous outpatient therapies (eg, pharmacotherapy, physiotherapy, etc.) and were referred to an inpatient, multidisciplinary program at the Red Cross Hospital, Kassel, Germany. Patients were included in the study if they met the following criteria: age over 18 years and diagnosed with chronic pain according to ICD-11 criteria. ${ }^{43}$ This was assessed by pain specialists who determined the pain diagnoses based on history, clinical bedside examinations and whatever diagnostic methods were considered appropriate (eg, imaging techniques). The most common diagnosis in the study population was nonspecific low back pain (72.7\%), followed by fibromyalgia (10.7\%), osteoarthritis (9\%) and rheumatoid arthritis (7.6\%).

The following exclusion criteria were applied: a pain history less than six months, presence of a malignant disease, severe medical or psychiatric illness interfering with pain assessment and inability to comprehend the German language.

The mean age of the participating patients was 59.71 years old $(\mathrm{SD}=13.79)$ which ranged from age $18-87$ years. The majority of patients were women (69.7\%). Most patients were married (58.9\%) and approximately $47.9 \%$ of the patients had primary education (Table 1). The average length of inpatient multidisciplinary treatment for patients was 15.03 days $(\mathrm{SD}=4.49$; Table 1$)$.

All participants gave written informed consent. The study was approved by the Ethics Committee of the Georg-Elias-Mueller Institute of Psychology.

\section{Pain treatment program}

Patients referred to the pain treatment center were enrolled in an inpatient multidisciplinary program lasting 15 consecutive days on average. The main goal of the intervention was to teach patients to cope with pain and to reduce the interference of pain with daily living. Based on a multidisciplinary approach, every patient was assessed by every specialty participating in the program. The multidisciplinary team involved specialized therapists including orthopedic physicians, rheumatologists, neurologists, psychotherapists and physiotherapists, as well as occupational therapists and social workers. The treatment included pharmacotherapy, physical approaches (such as exercise, physiotherapy, physical therapy and rehabilitation), psychological strategies
Table I Sample characteristics $(\mathrm{n}=279)$

\begin{tabular}{|c|c|}
\hline Characteristic & Value \\
\hline Age, Mean (SD), years & $59.7 \mid(13.79)$ \\
\hline \multicolumn{2}{|l|}{ Sex, No (\%) } \\
\hline Female & 193 (69.7\%) \\
\hline \multicolumn{2}{|l|}{ Marital status, No (\%) } \\
\hline Married & 162 (58.9\%) \\
\hline Single & $21(7.6 \%)$ \\
\hline Divorced/separated & $38(13.8 \%)$ \\
\hline Living with a partner & $24(8.7 \%)$ \\
\hline Widowed & $30(10.9 \%)$ \\
\hline \multicolumn{2}{|l|}{ Educational level, No (\%) } \\
\hline None & $8(3.0 \%)$ \\
\hline Primary education & $128(47.9 \%)$ \\
\hline Secondary education & 91 (34.1\%) \\
\hline High school certificate & $21(7.9 \%)$ \\
\hline University degree & $19(7.1 \%)$ \\
\hline Pain history, Mean (SD), (years) & $8.12(8.31)$ \\
\hline Number of hospital days, Mean (SD) & I5.03 (4.49) \\
\hline
\end{tabular}

Abbreviations: $M$, mean; SD, standard deviation.

including psychological counseling, cognitive-behavioral interventions, self-help strategies and the acquisition of pain management skills (eg, goal setting, structuring of daily activities, pacing strategies). The status of each patient, the extent of his/her recovery and the decision about his/her discharge time were regularly discussed at regular team meetings consisting of all members of the treatment team.

Before the start of program, patients were requested to complete the baseline assessment: demographic features, pain intensity, disability and psychological variables (T0). Immediately at the end of treatment program (T1) and three months after the end of the treatment (T2), the instruments for pain, disability assessment and the psychological instruments were reapplied and the posttreatment and follow-up scores were obtained.

\section{Measures}

In addition to the standard sociodemographic assessment (age, sex, marital status, educational level), the following variables were measured:

- Pain intensity was assessed with the Numeric Rating Scale (NRS; 0 (no pain) to 10 (worst imaginable pain)). Adequate psychometric properties have been reported. ${ }^{44}$ 
- Pain-related disability was measured by the Pain Disability Index (PDI). ${ }^{45}$ The PDI assesses subjective disability in seven areas: home/family responsibilities, recreation, social activities, occupation, sexual behavior, self-care and life support activities scored on an 11 -grade format ranging from ' 0 ' (no disability) to ' 10 ' (total disability). The PDI total score is calculated by summing the 7-items responses. A higher score indicates a higher level of disability. In a study by Dillmann et $\mathrm{al}^{46}$ the reliability (Cronbach's alpha=0.88) and validity of the German version of the instrument were confirmed. The construct validity of the scale was assessed by correlating the PDI score with the Oswestry Low Back Pain Disability Questionnaire $(r=0.76) .{ }^{46}$ This questionnaire indicated a good internal consistency in the present study (coefficient omega $=0.87,95 \%$ CI: $0.84-0.89$ ).

- Pain history was assessed by the question "How long have you been suffering from chronic pain". Participants were asked to indicate the number of years they have experienced pain.

- Depressive symptoms were assessed by the German short version of the Center for Epidemiological Studies Depression Scale (CES-D) ${ }^{47}$ This scale is a 15-item self-report scale from 0 (rarely) to 3 (most of the time), designed to measure depressive symptoms during the past days. The scale has been shown to be a reliable (Cronbach's alpha $=0.91$ ) measure of depression. ${ }^{48}$ The construct validity of the scale was assessed by correlating its total score with the other questionnaires such as Beck Depression Inventory $(\mathrm{r}=0.64-0.88)$ and the Patient Health Questionnaire $(\mathrm{r}=0.51-0.70){ }^{48-50}$ This scale has adequate internal consistency (coefficient omega $=0.84,95 \%$ CI: $0.83-$ 0.86 ) in the present sample.

- Catastrophizing cognitions concerning pain were measured with the German version of the Pain Catastrophizing Scale (subscale "helplessness"). ${ }^{51}$ The subscale "helplessness" describes the feeling of inability to cope with the pain. This subscale has shown the most appropriate construct validity compared to the other subscales of the PCS. ${ }^{51,52}$ It consists of six items answered on a 5-point scale ranging from 0 (not at all) to 4 (all the time). In a study by Meyer et al, ${ }^{51}$ the reliability (Cronbach's alpha $=0.89$ ) and validity of the German version of the instrument were confirmed. The construct validity of the "helplessness" subscale was assessed by correlating its total score with the other questionnaires such as Roland-Morris questionnaire $(\mathrm{r}=0.62)^{53}$ and the Fear Avoidance Beliefs Questionnaire-work subscale $(\mathrm{r}=0.62) .{ }^{54}$ The subscale demonstrated a good internal consistency in the present study (coefficient omega $=0.90,95 \%$ CI: $0.88-0.92$ ).

- Pain acceptance was measured by 10 items from the German version of the Chronic Pain Acceptance Questionnaire (CPAQ; items 1, 2, 6, 9, 11, 12, 13, 14, 15 and 18). ${ }^{55}$ These items showed the highest correlation with the total score of the questionnaire. Items were answered on a 7-point scale ranging from 0 (never) to 6 (always), with an internal consistency of Cronbach's alpha $=0.73 .{ }^{55}$ In a study by Nilges et al, the construct validity of the CPAQ was assessed by correlating its total score with the other questionnaires such as the Center for Epidemiological Studies Depression Scale (CES-D) $(\mathrm{r}=$ $0.0 .64)$ and the Pain Disability Index (PDI) $(\mathrm{r}=0.43){ }^{55}$ The selected items demonstrate an excellent internal consistency in the present study (coefficient omega $=0.92,95 \%$ CI: $0.90-0.94$ ).

\section{Statistical analysis}

To test whether multidisciplinary treatment leads to significant improvements in pain intensity, disability and psychological variables, repeated measures analysis of variance and Bonferroni post hoc tests were performed. Effect size was calculated by $\eta^{2}$ and Cohen's d. As suggested by Cohen, effect sizes are categorized as small $(\mathrm{d}=0.2)$, medium $(\mathrm{d}=0.5)$, and large $(\mathrm{d}=0.8) .{ }^{56}$

Before conducting regression and mediation analyses, we calculated residualized change scores as measures of change over time. To create residualized change scores, we used linear regression to predict follow-up scores from the baseline scores for the same variable, saving the standardized residual values as new variables. As these residual scores represent the difference between the follow-up score compared with what was predicted at baseline, they could control for baseline score. ${ }^{57,58}$ The residual values are frequently used in studies of mediation. ${ }^{32,57}$

Univariate regression analyses were used to evaluate the association of pain reduction (independent variable) with psychological changes. The changes in depression, pain catastrophizing and acceptance from pretreatment to follow-up (T0-T2) were entered as the dependent variables (Criterion).

The Hayes and Preacher ${ }^{59}$ Multiple Mediation Procedure (Indirect) was used to determine whether the relationship between reduction in pain intensity and disability was 
mediated by changes in depression, catastrophizing and pain acceptance (Figure 1) when controlling for age, sex and pain history. The Multiple Mediation Procedure (Indirect) involves estimating relative indirect effects in mediation models using multiple mediators after controlling for covariates. Inferences about indirect effects were on the basis of percentile bootstrap confidence intervals $(n=5,000$; confidence intervals to be set at 95\%). Bootstrapping is a sampling method that increases the precision of the constructed confidence intervals. According to Hayes and Preacher, ${ }^{59}$ if 0 is outside the confidence interval, then the relative indirect effect is deemed to be statistically different from 0 . Including three mediators and covariates in one model allowed us to determine the magnitude of the specific indirect effect of each mediator, conditional on the inclusion of the other mediators as well as covariates in he model. All of the data were analyzed using the IBM SPSS Statistics for Windows, version 22.0 (IBM Corp, Armonk,

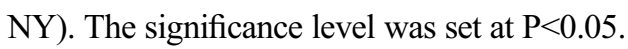

\section{Results}

\section{Study sample}

Of the 300 patients enrolled in the multidisciplinary program, 279 patients completed the study. Two patients refused to participate in the study. A total of 7 patients had to be excluded from the study: 5 patients because they had a pain history of less than 6 months and 2 patients in whom tumor or other medical illness interfering with pain assessment was diagnosed (eg, Alzheimer's disease). Moreover, 12 patients dropped out before completion of the study (at follow-up): 11 patients because of insufficient follow-up data for further evaluation and one patient due to rehospitalization related to pain during the follow-up period. All remaining patients $(n=279)$ completed the data at baseline, posttreatment and follow-up (Figure 2).

\section{Outcomes}

One-way repeated measures ANOVAs revealed that there were significant main effects of time (T0, T1, T2) on ratings of pain intensity $(\mathrm{F}(2 / 290)=68.61, P=0.000)$ and disability $(\mathrm{F}(2 / 288)=72.48, P=0.000)$. The psychological variables depression $(\mathrm{F}(2 / 264)=62.98, P=0.000)$, pain acceptance $(\mathrm{F}(2 / 284)=33.74, P=0.000)$ and catastrophizing $(\mathrm{F}(2 / 294)=39.99, P=0.000$, Table 2$)$ also showed a significant time effect.

As there was no control group in the current study, it cannot be identified whether outcomes were causally related to the treatment. However, the time effect

C
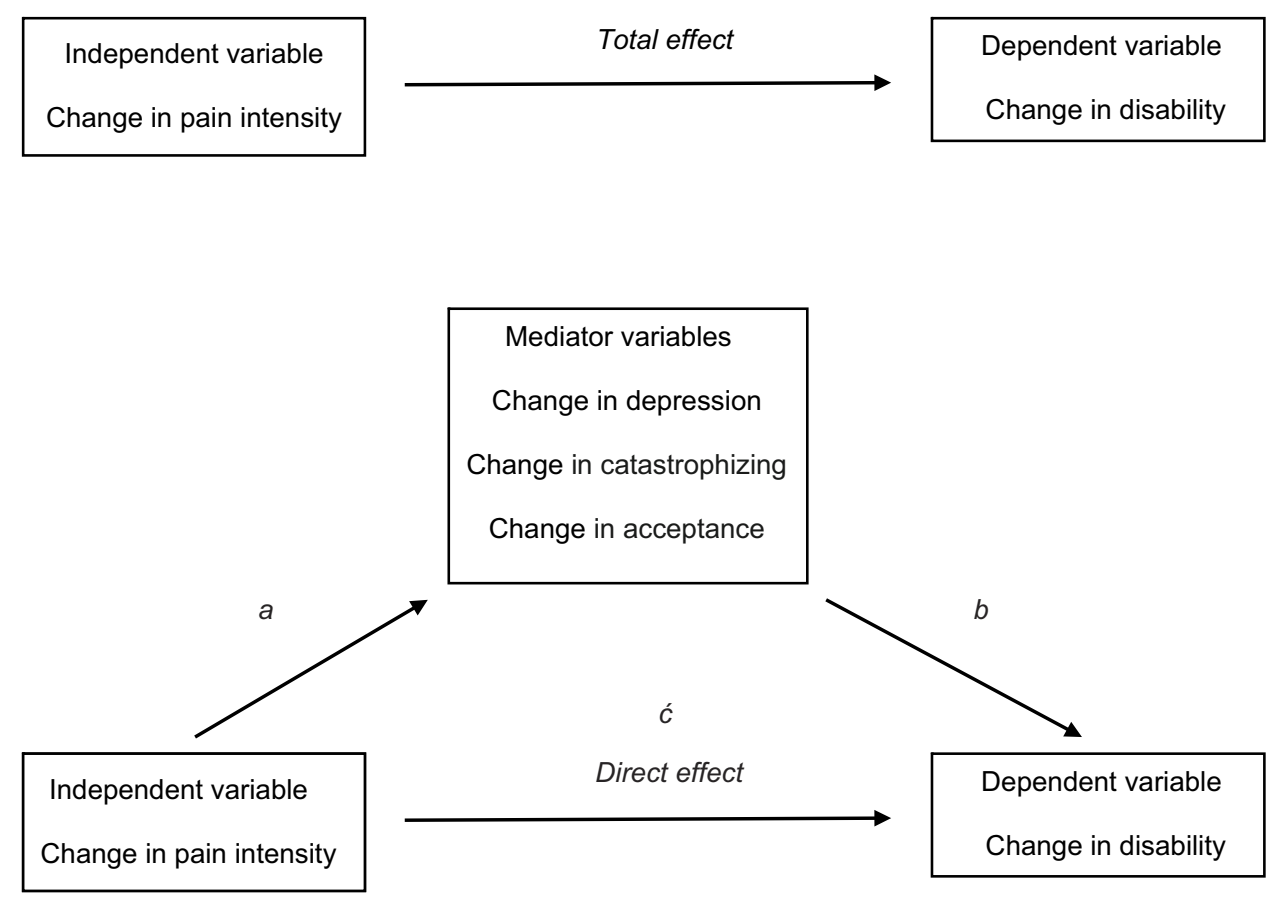

Figure I Model for the mediation analysis. The indirect effect is quantified by the product of paths a and b. The total effect (path c) is the sum of the indirect and direct (ć) effects. 


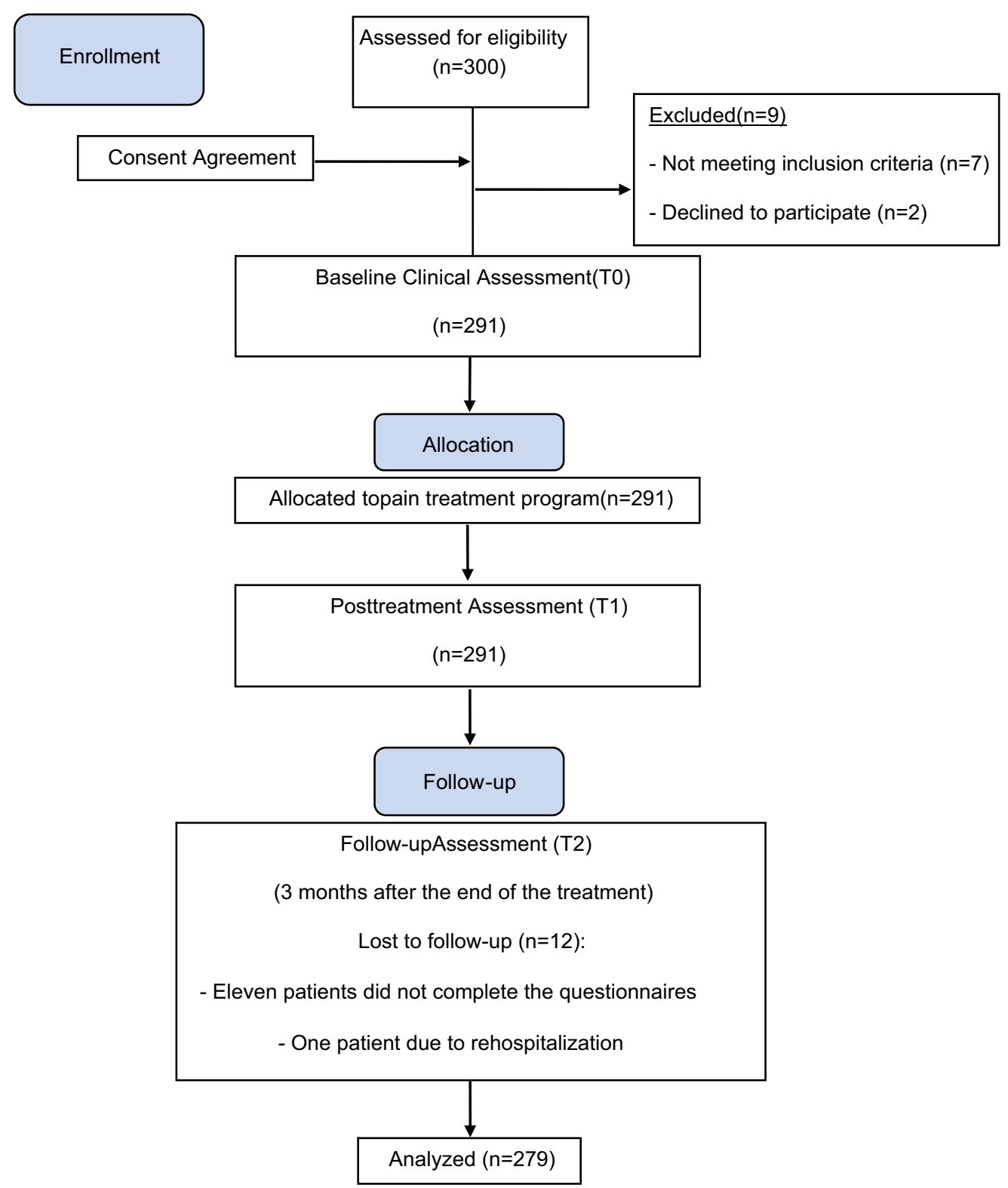

Figure 2 CONSORT flow diagram - modified for non-randomized trial design.

indicates that multidisciplinary treatment possibly led to a significant improvement in the pain condition, as shown in the reduction of pain intensity and disability at posttreatment and follow-up. Pairwise comparisons between pretreatment and posttreatment (T0-T1) and between pretreatment and follow-up (T0-T2) showed significant improvements in pain intensity and disability (Table 2). Similarly, the psychological mediators showed significant changes over time as shown by improvements in depression, pain acceptance and catastrophizing from pretreatment to posttreatment and to follow-up (Table 2).

\section{Univariate regression analyses}

After calculating residualized change scores (pre- to follow-up), linear regression analyses for each of the psychological variables were performed. Univariate regression analyses revealed that the change in pain intensity accounted for significant changes in depression, pain catastrophizing and pain acceptance (Table 3).

\section{Analysis of mediators}

Multiple Mediation Procedure was used to determine whether improvement in depression, pain catastrophizing 


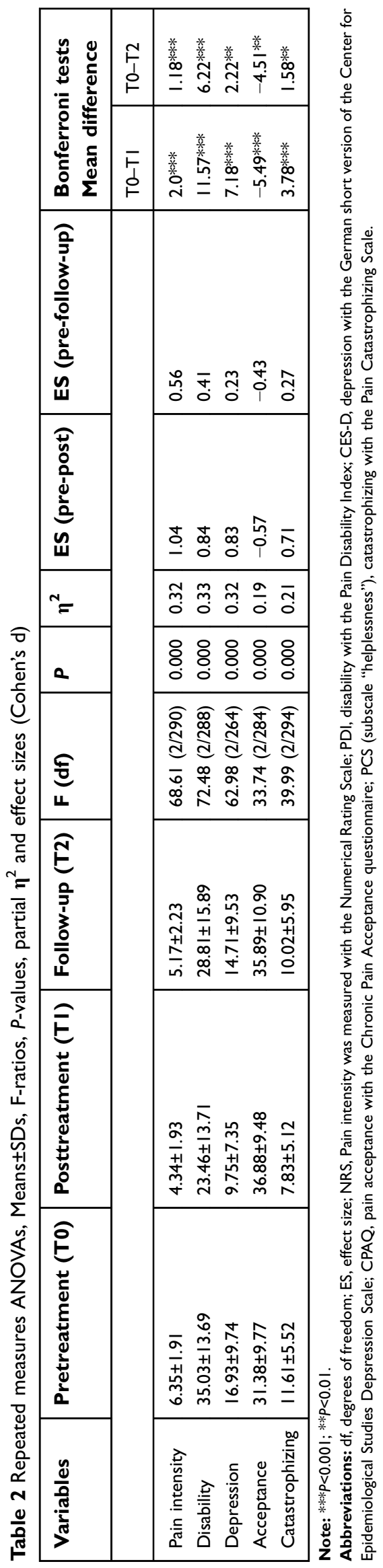

and pain acceptance mediated the relationship between reduction in pain intensity and disability after controlling for age, sex and pain history. The results revealed that changes in depression (95\% confidence interval, $0.01-$ $0.14)$, pain acceptance $(95 \%$ confidence interval, 0.10 $0.28)$ and catastrophizing ( $95 \%$ confidence interval, 0.005-0.17) mediated the association between reduction in pain and in disability (Table 4).

\section{Discussion}

Consistent with the treatment outcome literature, an inpatient multidisciplinary pain treatment program delivered in a specialized pain unit in Germany led to significant improvements in pain intensity, disability and psychological variables (depression, catastrophizing and acceptance). The results showed that pain reduction accounted for significant changes in psychological variables. Pain reduction did affect reduction in disability through improvement of depression, catastrophizing and acceptance even when controlling for age, sex and pain history.

As hypothesized, a multidisciplinary pain treatment program produced significant medium to large improvements in pain intensity and disability at posttreatment and follow-up. These findings are consistent with previous research showing positive effects of multidisciplinary treatment for chronic back pain, fibromyalgia, chronic widespread pain and neuropathic pain ${ }^{15,18,19,60}$ and lend further support to the beneficial effects of intensive inpatient multidisciplinary programs for adults with chronic musculoskeletal pain.

In line with our previous research on neuropathic pain patients, ${ }^{15}$ the present results show that musculoskeletal pain patients treated by a multidisciplinary program also demonstrated significant improvements in pain acceptance, catastrophizing and depression at posttreatment. These improvements remained stable over the three months following discharge. Although outcome research was not the primary goal of this study, the present findings contribute to a larger body of evidence indicating that inpatient multidisciplinary pain treatment is an empirically supported intervention for chronic pain.

The results also verified the assumption that pain reduction accounted for significant improvement in depression, pain catastrophizing and pain acceptance. This means that those patients who experienced more improvement in pain also experienced more improvement with regard to depression, catastrophizing and an increased pain acceptance. Consistently, Korff and Simon ${ }^{61}$ found 
Table 3 Results of univariate regression analyses on changes in psychological variables (depression, catastrophizing, acceptance)

\begin{tabular}{|c|c|c|c|c|c|c|}
\hline Predictor & Criterion & $\mathbf{R}^{2}$ & B & SEB & $\beta$ & $P$ \\
\hline \multirow[t]{3}{*}{ Change in pain intensity (T0-T2) } & Change in depression (T0-T2) & 0.15 & 1.17 & 0.22 & 0.39 & 0.000 \\
\hline & Change in catastrophizing (T0-T2) & 0.15 & 0.85 & 0.16 & 0.39 & 0.000 \\
\hline & Change in acceptance (T0-T2) & 0.19 & 1.67 & 0.27 & 0.44 & 0.000 \\
\hline
\end{tabular}

that back pain patients whose pain had improved at longterm follow-up showed markedly reduced depression levels at that time. ${ }^{61}$ One other study showed that declining pain following arthroscopy was associated with lower catastrophizing. ${ }^{40}$ Wade et $\mathrm{al}^{40}$ argued that individuals are more likely to catastrophize when they are in pain or their pain increases. They proposed that recovering from pain may lead to a down-regulation of vigilance to pain and to a sense of dread, thus affect catastrophizing cognitions. This assumption was also shared by Turner and Aaron ${ }^{39}$ who proposed that in certain situations, such as intense pain, catastrophizing increases. Although our study did not include a control group, and correlational findings do not shed light on causal relationships, the results add some further evidence to support the influence of pain intensity on the level of pain-related cognitions and emotions and a sense of helplessness. Our findings support the notion that, in contrast with the view of enduring personality traits (eg, neuroticism), pain-related cognitions like catastrophizing, depression and acceptance are dynamic features of the individuals related to the perceived intensity of pain and may vary over time dependent on the internal situation.

The current findings might suggest that regardless of the effect of psychological interventions (cognitive-behavioral interventions) on pain-related emotions and cognitions, reducing pain following physical therapies such as pharmacotherapy as a part of multidisciplinary treatment may influence pain-related emotions and cognitions in patients. It means that cognitive changes may be a secondary effect of behavioral exposure that occurs with pain reduction following directed and intensive physical therapies. Consistent with this, Burns et al (1998) ${ }^{62}$ showed that pre- to posttreatment changes in pain helplessness and treadmill endurance were correlated. They found that these factors accounted for much of the common variance in general activity and downtime changes. Although it cannot simply be concluded whether physical therapies or other therapeutic elements such as cognitive-behavioral interventions were primarily responsible for meaningful psychological changes, our results lend support to the notion that changes in maladaptive cognitions and emotions that occur during multidisciplinary treatment may be caused not only by psychological strategies, but rather by other activities taking place in a multidisciplinary program. Future research will need to examine whether patients assigned to either psychological interventions or physical therapy conditions show outcomes specific to psychological changes and whether psychological changes explain outcomes more accurately among those who undergo particular treatment approaches.

Cognitive-behavioral models of pain hypothesize a central role for cognitive emotional processing in the subjective experience of pain and its consequences, ie, feeling disabled and behaving correspondingly. The results of mediation analysis in the current study support this model. Our findings showed that pain reduction did affect the reduction in disability through improvement of depression, catastrophizing and acceptance. Examination of the bootstrap results for indirect effects suggests that improvement in pain acceptance accounts for most of this effect (Table 3). This result is consistent with previous research ${ }^{16,63,64}$ showing pain acceptance as the most important predictor of disability and its reduction after treatment. Research suggests that patients with high levels of acceptance are also able to open up to experiences that are beyond their control, which in turn results in less avoidant behaviors. ${ }^{65}$ Those patients who do not attempt to control or avoid sensations of pain are also less disabled by their pain. ${ }^{66}$ Altogether, reduction in pain following treatment may help patients to better deal with their pain and fosters its acceptance. Pain acceptance, in turn, results in resuming of activities of daily living and, thereby, contributes to a decrease in disability.

Another important finding of the present study was that changes in catastrophizing mediated the relationship between reduction in pain intensity and disability. Catastrophizing is a reflection of individuals' expectations about the actual and long-term consequences of pain. ${ }^{40} \mathrm{~A}$ reduction in pain intensity following a multidisciplinary treatment program may reduce the sense of dread in patients, which in turn results in less catastrophizing. This is consistent with previous findings in patients having total knee arthroplasty or physical therapy. ${ }^{40,63}$ Wade et al ${ }^{40}$ observed that as pain declined from before to six months after surgery for knee osteoarthritis, 


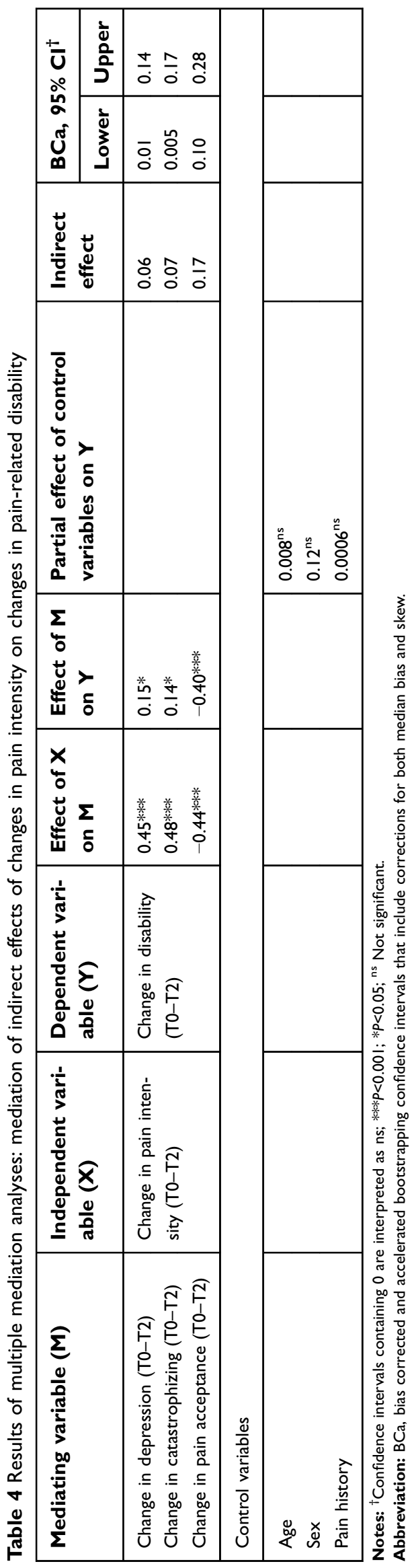

catastrophizing did as well. Our results are consistent with those of Jensen et $\mathrm{al}^{67}$ showing that a decrease in catastrophizing was associated with decreases in disability in chronic pain patients. Thus, disability can be reduced when the patient believes that pain will get better and that he/she is not helpless in coping with it.

Based on our results, a change in depression also mediated the relationship between reduction in pain intensity and disability. This finding is consistent with those of Glombiewski et al, ${ }^{68}$ who found significant contributions of decreased depression to improvement in pain-related disability. Pain reduction affects emotional distress and negative expectations regarding its consequences on the patient's life. The improvement in depressive symptoms may help patients to overcome their loss of interest in daily activities, which directly results in a reduction in disability in patients. However, we have to consider the correlation of the psychological variables depression, pain catastrophizing and acceptance, and that the observed results might reflect an overlap of these constructs. ${ }^{69}$

It is important to mention some of the limitations of our study. First, there was no control group in the current study. Thus, it is not possible to definitely determine whether the observed results were the effect of treatment. Nevertheless, as Maric argues, a single-group design can still contribute to an understanding of mediation processes, and this is indicated by several recent investigations of mediation in single-treatment groups. ${ }^{31,70}$ Another limitation of the study lies in the inclusion of a sample of middle-older aged patients from only a single clinic and, thus, prevents generalization. Assessing psychological variables based only on self-report questionnaires might endanger our findings. ${ }^{71}$ Furthermore, we used a shortened version of the Chronic Pain Acceptance Questionnaire and only one subscale of the Pain Catastrophizing Scale (subscale "helplessness"), perhaps undermining the utility of the instruments and thereby limiting the conclusions which can be drawn from the results. More research with stronger methodological quality and longer follow-up periods is needed in order to provide high-quality evidence of the effectiveness of multidisciplinary pain treatment for the management of chronic musculoskeletal pain.

In summary, our findings support cognitive-behavioral models of pain that posit an important role for pain-related thoughts and emotions in long-term outcomes following multidisciplinary pain treatment. The current findings are relevant to the management of patients with musculoskeletal pain. The results support the notion that, in contrast with the 
view of enduring personality traits, pain-related cognitions and emotions reflect a situational response that varies over time. Pain-related cognitions and emotions can be improved in pain patients by reducing the pain intensity and changing the way people think about anticipated harm. The results show that not only treatment elements that deliberately target cognitive and emotional factors but also physical therapies that let the patients experience physical exercise or normally hampered activities in a controlled environment are responsible for a substantial cognitive and emotional change.

\section{Ethical approval}

All procedures performed in studies involving human participants were in accordance with the ethical standards of the institutional and/or national research committee and with the 1964 Helsinki Declaration and its later amendments or comparable ethical standards.

\section{Informed consent}

Informed consent was obtained from all individual participants included in the study.

\section{Acknowledgments}

This research did not receive any specific grant from funding agencies in the public, commercial, or not-forprofit sectors.

\section{Disclosure}

The authors report no conflicts of interest in this work.

\section{References}

1. McBeth J, Jones K. Epidemiology of chronic musculoskeletal pain. Best Pract Res Clin Rheum. 2007;21:403-425. doi:10.1016/j. berh.2007.03.003

2. The Global Burden of Disease 2013 Collaborators. Global, regional, and national incidence, prevalence, and years lived with disability for 301 acute and chronic diseases and injuries in 188 countries, 1990-2013: a systematic analysis for the Global Burden of Disease Study 2013. Lancet. 2015;386:743-800. doi:10.1016/S0140-6736(15)61137-0

3. Schmidt CO, Baumeister SE. Simple patterns behind complex spatial pain reporting? Assessing a classification of multisite pain reporting in the general population. Pain. 2007;133:174-182. doi:10.1016/j. pain.2007.03.019

4. Carnes D, Parsons S, Ashby D, et al. Chronic musculoskeletal pain rarely presents in a single body site: results from a UK population study. Rheumatology. 2007;46:1168-1170. doi:10.1093/rheumatology/ kem045

5. Buchman AS, Shah RC, Leurgans SE, Boyle PA, Wilson RS, Bennett DA. Musculoskeletal pain and incident disability in community-dwelling older adults. Arthritis Care Res. 2010;62(9):1287-1293. doi: $10.1002 /$ acr. 20200
6. Murray CJ, Richards MA, Newton JN, et al. UK health performance: findings of the Global Burden of Disease Study 2010. Lancet. 2013;381:997-1020. doi:10.1016/S0140-6736(13)60355-4

7. Park PW, Dryer RD, Hegeman-Dingle R, et al. Cost burden of chronic pain patients in a large integrated delivery system in the United States. Pain Pract. 2016;16(8):1001-1011. doi:10.1111/ papr. 12357

8. Turk DC. Cognitive-behavioral approach to the treatment of chronic pain patients. Reg Anesth Pain Med. 2003;28(6):573-579.

9. Turner JA, Romano JM. Cognitive-behavioral therapy for chronic pain. In: Loeser JD, editor. Bonica's Management of Pain. Philadelphia: Lippincott Williams \& Wilkins; 2001:1751-1758.

10. Sullivan MJ, Thorn B, Haythornthwaite JA, et al. Theoretical perspectives on the relation between catastrophizing and pain. Clin $J$ Pain. 2001;17(1):52-64. doi:10.1097/00002508-200103000-00008

11. Hayes SC. Acceptance and commitment therapy, relational frame theory, and the third wave of behavioral and cognitive therapies. Behav Ther. 2004;35(4):639-665. doi:10.1016/S0005-7894(04) 80013-3

12. McCracken LM. Learning to live with the pain: acceptance of pain predicts adjustment in persons with chronic pain. Pain. 1998;74 (1):21-27. doi:10.1016/S0304-3959(97)00146-2

13. McCracken LM, Eccleston C. A comparison of the relative utility of coping and acceptance-based measures in a sample of chronic pain sufferers. Eur J Pain. 2006;10(1):23-29. doi:10.1016/j.ejpain.2005.01.004

14. Baranoff J, Hanrahan SJ, Kapur D, Connor JP. Acceptance as a process variable in relation to catastrophizing in multidisciplinary pain treatment. Eur J Pain. 2013;17(1):101-110. doi:10.1002/ j.1532-2149.2012.00165.x

15. Shaygan M, Böger A, Kröner-Herwig B. Predicting factors of outcome in multidisciplinary treatment of chronic neuropathic pain. $J$ Pain Res. 2018;11:2433-2443. doi:10.2147/JPR.S175817

16. Burns JW, Glenn B, Bruehl S, Harden RN, Lofland K. Cognitive factors influence outcome following multidisciplinary chronic pain treatment: A replication and extension of a cross-lagged panel analysis. Behav Res Ther. 2003;41:1163-1182.

17. Burns JW, Kubilus A, Bruehl S, Harden RN, Lofland K. Do changes in cognitive factors influence outcome following multidisciplinary treatment for chronic pain? A cross-lagged panel analysis. J Consult Clin Psychol. 2003;71:81-91. doi:10.1037/0022-006X.71.1.81

18. Shaygan M, Böger A. Predictive factors of reducing disability in multidisciplinary treatment of chronic pain. $J$ Mazandaran Univ Med Sci. 2019;28(169):65-74.

19. Boonstra AM, Reneman MF, Waaksma BR, Schiphorst Preuper HR, Stewart RE. Predictors of multidisciplinary treatment outcome in patients with chronic musculoskeletal pain. Disabil Rehabil. 2015;37(14):1242-1250. doi:10.3109/09638288.2014.961657

20. Costa LDCM, Maher CG, McAuley JH, Hancock MJ, Smeets RJEM. Self efficacy is more important than fear of movement in mediating the relationship between pain and disability in chronic low back pain. Eur J Pain. 2011;15:213-219. doi:10.1016/j. ejpain.2010.06.014

21. Hall AM, Kamper SJ, Maher CG, Latimer J, Ferreira ML, Nicholas MK. Symptoms of depression and stress mediate the effect of pain on disability. Pain. 2011;152:1044-1051. doi:10.1016/j.pain.2011.02.053

22. Lee H, Hübscher M, Moseley GL, et al. How does pain lead to disability? A systematic review and meta-analysis of mediation studies in people with back and neck pain. Pain. 2015;156(6):988-997. doi:10.1097/j.pain.0000000000000146

23. Marshall PW, Schabrun S, Knox MF. Physical activity and the mediating effect of fear, depression, anxiety, and catastrophizing on pain related disability in people with chronic low back pain. PLoS One. 2017;12(7):e0180788. doi:10.1371/journal.pone.0180788

24. Mansell G, Kamper SJ, Kent P. Why and how back pain interventions work: what can we do to find out? Best Pract Res Clin Rheum. 2013;27(5):685-697. doi:10.1016/j.berh.2013.10.001 
25. Turner JA, Holtzman S, Mancl L. Mediators, moderators, and predictors of therapeutic change in cognitive-behavioral therapy for chronic pain Pain. 2007;127(3):276-286. doi:10.1016/j.pain.2006.09.005

26. Smeets RJ, Vlaeyen JW, Kester AD, Knotterus JA. Reduction of pain catastrophizing mediates the outcome of both physical and cognitivebehavioral treatment in chronic low back pain. J Pain. 2006;7 (4):261-271. doi:10.1016/j.jpain.2005.10.011

27. Spinhoven P, Ter Kuile M, Kole-Snijders AM, Hutten Mansfeld M, Den Ouden DJ, Vlaeyen JW. Catastrophizing and internal pain control as mediators of outcome in the multidisciplinary treatment of chronic low back pain. Eur J Pain. 2004;8(3):211-219. doi:10.1016/j. ejpain.2003.08.003

28. Focht BC, Rejeski WJ, Ambrosius WT, Katula JA, Messier SP. Exercise, self-efficacy, and mobility performance in overweight and obese older adults with knee osteoarthritis. Arthritis Rheumatism. 2005;53(5):659-665. doi:10.1002/art.21466

29. Seymour RB, Hughes SL, Campbell RT, Huber GM, Desai P. Comparison of two methods of conducting the fit and strong!, program. Arthritis Rheumatism. 2009;61(7):876-884. doi:10.1002/ art. 24517

30. Wicksell RK, Olssen GL, Hayes SC. Psychological flexibility as a mediator of improvement in acceptance and commitment therapy for patients with chronic pain following whiplash. Eur J Pain. 2010;14 (10):e1-11. doi:10.1016/j.ejpain.2010.05.001

31. Vowles KE, Witkiewitz K, Sowden G, Ashworth J. Acceptance and commitment therapy for chronic pain: evidence of mediation and clinically significant change following an abbreviated interdisciplinary program of rehabilitation. $J$ Pain. 2014;15(1):101-113. doi:10.1016/j.jpain.2013.10.002

32. Mansell G, Hill JC, Main C, Vowles KE, van der Windt D. Exploring what factors mediate treatment effect: example of the STarT back study high-risk intervention. J Pain. 2016;17(11):1237-1245. doi:10.1016/j.jpain.2016.08.005

33. Wertli MM, Burgstaller JM, Weiser S, Steurer J, Kofmehl R, Held U. Influence of catastrophizing on treatment outcome in patients with nonspecific low back pain: a systematic review. Spine. 2014;39 (3):263-273. doi:10.1097/BRS.0000000000000110

34. Barnhoorn KJ, Staal JB, van Dongen RT, et al. Are pain-related fears mediators for reducing disability and pain in patients with complex regional pain syndrome type 1 ? An explorative analysis on pain exposure physical therapy. PLoS One. 2015;10(4):e0123008. doi:10.1371/journal.pone.0123008

35. Goubert L, Crombez G, Van Damme S. The role of neuroticism, pain catastrophizing and pain-related fear in vigilance to pain: a structural equation's approach. Pain. 2004;107:234-241. doi:10.1016/j. pain.2003.11.005

36. Gracely RH, Geisser ME, Gieseke T, et al. Pain catastrophizing and neural responses to pain among persons with fibromyalgia. Brain. 2004;127:835-843. doi:10.1093/brain/awh098

37. Sullivan MJ, Lynch ME, Clark AJ. Dimensions of catastrophic thinking associated with pain experience and disability in patients with neuropathic pain conditions. Pain. 2005;113:310-315. doi:10.1016/j. pain.2004.11.003

38. Vlaeyen JW, Timmermans C, Rodriguez LM, et al. Catastrophic thinking about pain increases discomfort during internal atrial cardioversion. J Psychosom Res. 2004;56:139-144. doi:10.1016/S00223999(03)00081-3

39. Turner JA, Aaron LA. Pain-related catastrophizing: what is it? Clin J Pain. 2001;17:65-71. doi:10.1097/00002508-200103000-00009

40. Wade JB, Riddle DL, Thacker LR. Is pain catastrophizing a stable trait or dynamic state in patients scheduled for knee arthroplasty? Clin J Pain. 2012;28(2):122-128. doi:10.1097/AJP.0b013e31822cf542

41. Dorner TE, Muckenhuber J, Stronegger WJ, Ràsky É, Gustorff B, Freidl W. The impact of socio-economic status on pain and the perception of disability due to pain. Eur J Pain. 2011;15(1):103109. doi:10.1016/j.ejpain.2010.05.013
42. Casey CY, Greenberg MA, Nicassio PM, Harpin RE, Hubbard D. Transition from acute to chronic pain and disability: a model including cognitive, affective, and trauma factors. Pain. 2008;134(1-2):69 79. doi:10.1016/j.pain.2007.03.032

43. Treede RD, Rief W, Barke A, et al. A classification of chronic pain for ICD-11. Pain. 2015;156(6):1003.

44. Williamson A, Hoggart B. Pain: a review of three commonly used pain rating scales. J Clin Nurs. 2005;14:798-804. doi:10.1111/j.13652702.2005.01121.x

45. Pollard CA. Preliminary validity study of Pain Disability Index. Percept Mot Skills. 1984;59:974-981. doi:10.2466/pms.1984.59.3.974

46. Dillmann U, Nilges P, Saile H, Gerbershagen HU. Assessing disability in chronic pain patients. Schmerz. 1994;8:100-110. doi:10.1007/ BF02530415

47. Radloff LS. The CES-D scale: a self-report depression scale for research in the general population. Appl Psychol Meas. 1977;1:385401. doi:10.1177/014662167700100306

48. Hautzinger M, Bailer M. Allgemeine Depressionsskala [General Depression Scale]. 1. Auflage. Göttingen, Germany: Beltz Test GmbH; 1993. German.

49. Hautzinger M. Die CES-D Skala. Ein Depressionsinstrument für Untersuchungen in der Allgemeinbevölkerung. Diagnostica. 1988;34:167-173.

50. Hautzinger M, Bailer M, Hofmeister D, Keller F. ADS: Allgemeine Depressionsskala (2. Überarbeitete, Neu Normierte Auflage). Göttingen: Hogrefe; 2012.

51. Meyer K, Sprott H, Mannion AF. Cross-cultural adaptation, reliability, and validity of the German version of the pain catastrophizing scale. $J$ Psychosom Res. 2008;64:469-478. doi:10.1016/j.jpsychores.2007.12.004

52. Sullivan MJ, Bishop SR, Pivik J. The pain catastrophizing scale: development and validation. Psychol Assess. 1995;7(4):524. doi:10.1037/1040-3590.7.4.524

53. Roland M, Fairbank J. The Roland-Morris disability questionnaire and the Oswestry disability questionnaire. Spine. 2000;25:31153124. doi:10.1097/00007632-200012150-00006

54. Waddell G, Newton M, Henderson I, Somerville D, Main CJ. A FearAvoidance Beliefs Questionnaire (FABQ) and the role of fearavoidance beliefs in chronic low back pain and disability. Pain. 1993;52:157-168.

55. Nilges P, Köster B, Schmidt CO. Schmerzakzeptanz-Konzept und Überprüfung einer deutschen Fassung des Chronic Pain Acceptance Questionnaire [Pain acceptance - concept and validation of a German version of the Chronic Pain Acceptance Questionnaire]. Schmerz. 2007;21:57-67. German. doi:10.1007/s00482-006-0508-1

56. Cohen J. Statistical Power Analysis for the Behavioral Sciences. New York, NY: Routledge Academic; 1988.

57. George SZ, Zeppieri G, Cere AL, et al. A randomized trial of behavioral physical therapy interventions for acute and sub-acute low back pain (NCT00373867). Pain. 2008;140:145-157. doi:10.1016/j.pain.2008.07.029

58. MacKinnon DP. Introduction to Statistical Mediation Analysis. New York: Taylor \& Francis Group; 2008.

59. Preacher KJ, Hayes AF. Asymptotic and resampling strategies for assessing and comparing indirect effects in multiple mediator models. Behav Res Methods. 2008;40:879-891.

60. de Rooij A, van der Leeden M, Roorda LD, Steultjens MP, Dekker J. Predictors of outcome of multidisciplinary treatment in chronic widespread pain: an observational study. BMC Musculoskelet Disord. 2013;14(1):133. doi:10.1186/1471-2474-14-133

61. Von Korff M, Simon G. The relationship between pain and depression. Br J Psychiatry Suppl. 1996;168(30):101-108. doi:10.1192/ S0007125000298474

62. Burns JW, Johnson BJ, Mahoney N, Devine J, Pawl R. Cognitive and physical capacity process variables predict long-term outcome following treatment of chronic pain. J Consult Clin Psychol. 1998;66:434-439. doi:10.1037/0022-006X.66.2.434 
63. Doménech J, Sanchis-Alfonso V, Espejo B. Changes in catastrophizing and kinesiophobia are predictive of changes in disability and pain after treatment in patients with anterior knee pain. Knee Surg Sports Traumatol Arthrosc. 2014;22(10):2295-2300. doi:10.1007/s00167-014-2968-7

64. Samwel HJ, Kraaimaat FW, Crul BJ, Dongen RD, Evers AW. Multidisciplinary allocation of chronic pain treatment: effects and cognitive-behavioural predictors of outcome. $\mathrm{Br} J$ Health Psychol. 2009;14(3):405-421. doi:10.1348/135910708X337760

65. McCracken LM, Gutierrez-Martinez O. Processes of change in psychological flexibility in an interdisciplinary groupbased treatment for chronic pain based on acceptance and commitment therapy. Behav Res Ther. 2011;49:267-274. doi:10.1016/j.brat.2011.02.004

66. McCracken LM, Vowles KE, Eccleston C. Acceptance of chronic pain: component analysis and a revised assessment method. Pain. 2004;107(1):159-166. doi:10.1016/j.pain.2003.10.012

67. Jensen MP, Turner JA, Romano JM. Changes after multidisciplinary pain treatment in patient pain beliefs and coping are associated with concurrent changes in patient functioning. Pain. 2007;131(1):38-47. doi:10.1016/j.pain.2006.12.007
68. Glombiewski JA, Hartwich-Tersek J, Rief W. Depression in chronic back pain patients: prediction of pain intensity and pain disability in cognitive-behavioral treatment. Psychosomatics. 2010;51(2):130136. doi:10.1016/S0033-3182(10)70673-3

69. Gillanders DT, Ferreira NB, Bose S, Esrich T. The relationship between acceptance, catastrophizing and illness representations in chronic pain. Eur J Pain. 2013;17(6):893-902. doi:10.1002/j.15322149.2012.00248.x

70. Maric M, Heyne DA, MacKinnon DP, Van Widenfelt BM, Westenberg PM. Cognitive mediation of cognitive-behavioural therapy outcomes for anxiety-based school refusal. Behav Cogn Psychother. 2013;41(5):549-564. doi:10.1017/S135246581200 0756

71. Shaygan M, Boeger A, Kroener-Herwig B. Neuropathic sensory symptoms: association with pain and psychological factors. Neuropsychiatr Dis Treat. 2014;10:897. doi:10.2147/NDT. S61492

\section{Publish your work in this journal}

The Journal of Pain Research is an international, peer reviewed, open access, online journal that welcomes laboratory and clinical findings in the fields of pain research and the prevention and management of pain. Original research, reviews, symposium reports, hypothesis formation and commentaries are all considered for publication. The manuscript management system is completely online and includes a very quick and fair peer-review system, which is all easy to use. Visit http:// www.dovepress.com/testimonials.php to read real quotes from published authors. 